\title{
Methyl Donors Supplementation Attenuates the Adverse Effects of Maternal High Fructose Diet of Offspring Emotional and Cognitive Behaviors
}

\author{
Sidi Mohamed Coulibaly ${ }^{1 *}$, Abdelhalem Mesfioui ${ }^{1}$, Ali Ouichou', Pacôme Kouadio N'Go², \\ Amina El Hasnaoui ${ }^{1}$, Abdeljabbar Nassiri ${ }^{1}$, Aboubaker El Hessni ${ }^{1}$ \\ ${ }^{1}$ Laboratory of Genetics, Neuroendocrinology and Biotechnology, Faculty of Sciences, University Ibn Tofail, Kenitra, Morocco \\ ${ }^{2}$ Training and Research Unit of Biology Sciences, Peleforo Gon Coulibaly University, Korhogo, Ivory Coast \\ Email: *sidicoulibaly2010@hotmail.fr
}

How to cite this paper: Coulibaly, S.M., Mesfioui, A., Ouichou, A., N'Go, P.K., El Hasnaoui, A., Nassiri, A. and El Hessni, A. (2017) Methyl Donors Supplementation Attenuates the Adverse Effects of Maternal High Fructose Diet of Offspring Emotional and Cognitive Behaviors. Open Journal of Endocrine and Metabolic Diseases, 7, 203 218.

https://doi.org/10.4236/ojemd.2017.711018

Received: October 21, 2017

Accepted: November 27, 2017

Published: November 30, 2017

Copyright ( $\odot 2017$ by authors and Scientific Research Publishing Inc. This work is licensed under the Creative Commons Attribution International License (CC BY 4.0).

http://creativecommons.org/licenses/by/4.0/

\section{c) (i) Open Access}

\begin{abstract}
Free Fatty acid is an end-product of hepatic metabolism of fructose. Most of past studies have demonstrated significant relationship between gestational high fat diet and metabolic and physiology outcomes in offspring. However, there is a scarce of data extended to the effects of high fructose diet-fed dams on juveniles' progeny. Therefore, the present experiment was designed to examine the later effects of maternal high fructose diet intake during pregnancy and lactation on juvenile offspring rats emotional behaviors and memory abilities. We tested whether methyl donors supplemented to that high fructose diet could reverse the adverse effects. We found at two months of age, anxiety-like behavior and depression-like behavior were elevated in off springs of mother fed to high fructose diet and a sex difference effect with males were more affected than females. In addition, behavioral outcomes indicated that the high fructose diet also impaired spatial working and recognition memories in the Y-maze and object recognition test respectively. Blood glucose intolerance increased significantly in juvenile males rats of dams fed with high fructose diet when compared to females. However, a supplementation of the maternal diet with methyl donors attenuated all these changes. Our study suggested a controlled fructose diet supplemented to methyl donors during critical period of brain developing (in utero and pre-weaning stage), otherwise that could induced irreversible detrimental effects on offspring behavior and cognitive health.
\end{abstract}

\section{Keywords}

High Fructose Diet, Methyl Donors, Anxiety-Like, Depressive-Like, Memory, Glucose Intolerance, Rat Offspring 


\section{Introduction}

Fructose is a monosaccharide compound present in significant quantities in fruit, soft drink and others sweetened beverages, and commonly found in western countries people diets. For instance, fructose constitutes approximately $8 \%$ of total daily energy intake in the United States [1], and the adolescents (12 - 18 years old) food consumption are particularly rich in fructose. However to date, the increasing of middle income in southern countries associated to nutritional transition based on high fat-diet or sugar-diet can be detrimental to health.

Maternal typical diet during pregnancy and lactation has a potential factor to influence long lasting on offspring phenotype, and most of studies have focused on the adverse health effects subsequent to high-fat diet during critical period of development. It has been so reported that excessive gestational weight gain due to high-fat diet, increases the risk of obesity in offspring, using both human and rodent models [2] [3] [4] [5]. Indeed, a past study had investigated the relation to dams fed with specific diet (high fat deprived of methyl donors) during pregnancy and lactation, and offspring physiology effects such as a global decrease of DNA methylation (essential factor in gene expression control) within the brains of males offspring [6]. Taken together, these are risk factors for neuroinflammatory diseases such asdiabetes, cardiovascular diseases, hypertension and brain diseases [7] [8] [9] [10].

Otherwise, some studies advanced the hypothesis of the existence of a relationship between high fructose consumption and hepatic metabolic disorders leading to an elevated of free fatty acids, Low Density Lipoprotein (LDL), insulin resistance and glucose intolerance [11] [12] [13] [14]. Although, it is also wellknown that liver's metabolism of fructose provides some precursors of free fatty acids and triacylglyceride such as acyl-coA and Very Low Density Lipoprotein (VLDL) respectively [15] [16], as well as some metabolites which entering the gluconeogenic pathway.

Given this background, and based on the tight metabolic relation between fructose and dyslipidemia, insulin resistance and neuroinflammation, current study emphasized on the extended effects of maternal consumption of high fructose-diet (HFD) during pregnancy and lactation on long-lasting emotional development and memory abilities of juveniles offspring even if they feed with standard diet during the post-weaning period, and whether a methyl donors supplementation during the maturing of brain could reverse adverse effects of HFD.

\section{Materials and Methods}

\subsection{Animals}

Current experiment was performed using both sexes of the Wistar rat strain (100 $\pm 5 \mathrm{~g}^{-6}$ weeks old). The rats were obtained in a local breeding colony in the laboratory of Genetics, Biotechnology and Neuroendocrinology located at Ibn Tofail University (Kenitra, Morocco). Animals were born and housed at con- 
trolled room temperature $\left(22^{\circ} \mathrm{C} \pm 2^{\circ} \mathrm{C}\right)$, humidity $(50 \%-60 \%)$, under a $12 \mathrm{~h}$ light/12 dark cycle (light at 7:00 am). They had free access to tap drinking water and standard commercial diet (ALF SAHEL Food Company of Casablanca, Morocco). That diet consisted to $13 \%$ of Crudeprotein susbstances, $2 \%$ of Fat matters, $0.3 \%$ of Phosphorus, $1 \%$ of Calcium and $9 \%$ of some others Mineral matters, $15 \%$ of Cellulose, 500 IU of Vitamin A, 75 IU of Vitamin D and 1 IU of Vitamin E.

\subsection{Experiment Groups and Treatment}

\subsubsection{Nutritional Feature during Pre-Mating Period}

At sexual maturity, animals were randomly divided into two groups: 1) the control's group of fertile male and females had only free access to standard diet during 8 weeks, 2) in the same time the study's group was fed daily with $50 \mathrm{~g}$ of standard diet and 23\% HFD (w/v) as solution in $30 \mathrm{ml}$ baby bottle [17]. Animals were weighed onset and weekly during 8 weeks.

\subsubsection{Nutritional Programming of the Offspring}

During pregnancy, females are assigned into 3 groups: 1) a control group received still a standard diet, 2) was fed in addition with a supplementation of $23 \%$ HFD (w/v) and 3 ) received by gavage simultaneously the fructose diet and nutrients rich in methyl donors (Cholin, $500 \mathrm{mg}$; Betain, $500 \mathrm{mg}$; Folic acid, 0.5 mg; Vitamin B12, $0.05 \mathrm{mg}$; L-methionin, $750 \mathrm{mg}$ ). Pregnant dams of each group were fed with the respective diet during pregnancy and lactation period. At weaning moment, their pups ( $\mathrm{n}=6$ per group) were submitted to growth diet by a free access to food up adult stage. Otherwise, the component of methyl donors a forementioned was adjusted from some papers [18] [19]. After several assays, this composition appeared to be non-toxic when given by gavage to animals.

\subsection{Behavioral Assessment}

At adulthood stage (60 - 70 days of age), affective behavior and cognitive abilities were assessed using Elevated Plus-Maze (EPM), Forced Swimming Test (FST), Y-Maze Test and Object Recognition Test.

\subsubsection{Elevated Plus-Maze}

EPM is dedicated to the assessment of rat's model of Anxiety-like behavior. The apparatus consisted to four open arms, $50 \mathrm{~cm}$ long and $10 \mathrm{~cm}$ wide. The arms are crossed in a central square platform $(10 \mathrm{~cm} \times 10 \mathrm{~cm})$, with two enclosedarms (by $40 \mathrm{~cm}$-high walls) and two open arms. The apparatus elevated to $50 \mathrm{~cm}$ above the floor.

The central platform was illuminated with a halogen lamp of 100 Was an aversive stimulus for the rats. Testing began by placing animals onto the platform facing to an open arm and $5 \mathrm{~min}$ were allowed them to explore freely the apparatus. We used alcohol solution for cleaning all olfactory cues between each evaluation [20]. The number of entries and time spent in the open arm was recorded by video camera for subsequent analysis. 


\subsubsection{Forced Swimming Test}

Swimming test is sensitive to depression-like behavior level of the rat. The testing took place in a glass cylinder $(50 \mathrm{~cm}$, depth; $30 \mathrm{~cm}$, diameter) with water $\left(23^{\circ} \mathrm{C} \pm 2^{\circ} \mathrm{C}\right)$ filled up $30 \mathrm{~cm}$. The session began by introducing rats in the apparatus and were individually forced to swim for $5 \mathrm{~min}$. The latency time up immobility and the duration of immobility were recorded. The immobility is defined when rat ceased any activities (i.e. struggling, swimming and jumping) and stay floating or make minimal movement with head kept above water. Moreover, the percentage of floating time increase with depression like response state [21].

\subsection{Spontaneous Alternation Behavior (Y-Maze Test)}

The Y-maze test consisted to a black painted wood with three arms ( $40 \mathrm{~cm}$ long, $12-\mathrm{cm}$ high, $3 \mathrm{~cm}$ at the bottom, and $10 \mathrm{~cm}$ wide at the top) having at their intersection a central triangle platform. This test assesses the immediate working memory ability which is correlated to spontaneous alteration behavior by a single session in the Y-maze [22]. The procedure was basically as described elsewhere [23]. Each rat, naïve to the maze was placed at the end of one arm and allowed to move freely through the maze during an 8-min session. The series of arm entries was recorded visually. An entry was considered to be completed when the hind paws of the mouse being in the arm. Alteration was defined as successive entries into the three different $\operatorname{arms}(\mathrm{A}, \mathrm{B}$ or $\mathrm{C}$ ) on overlapping triplet sets (i.e. $\mathrm{ACBABACBAB}=5$ alternations). Percentage of alternation was calculated as following: $\%$ alternation $=$ number of alternation $/($ total arm entries -2$) \times 100$.

\subsubsection{Object Recognition Test (ORT)}

The ORT is carried out in an open box to evaluate the preference for the novel object than the familiar one. The apparatus was homogeneously lighted (600 lux). The procedure was as described by Ennaceur and Delacour (1988) with some modifications.

The habituation phase on the first test day, rats explored the empty arena for $10 \mathrm{~min}$.

The next day, they were allowed $5 \mathrm{~min}$ to explore the arena with two identical objects (same color, shape and texture) locate at the opposite corners: acquisition phase. On the following day, the retention phase consisted to test the rats with one familiar object previously encountered and the other novel one for $5 \mathrm{~min}$. After each test, the box and objects were cleaned with $70 \%$ ethanol. The exploration behavior is only considered as "directing the nose at a distance about $1 \mathrm{~cm}$ from the objects." We have taken account two parameters. (1) \% Recognition Index (RI) was calculated as time spent to explore the novel object divided by total time spent for both object, (2) Discrimination index (DI, the object preference) was times spent to explore novel object minus that of familiar one divided by the time for both object. The threshold of 50\% and positive score expressed the recognition and the preference of novel object respectively [24]-[30]. 


\subsubsection{Intraperitoneal Glucose Tolerance Test}

This test was conducted to study glucose tolerance behavior related to high fructose diet. After a fasting period of $12 \mathrm{~h}$, blood sample was taken from tail vein at $\mathrm{T} 0$. Then, rats were intraperitoneally injected with glucose solution at 2 $\mathrm{g} / \mathrm{kg}$ b. wand blood was taken at T30, T60, T90 and T120 min. The blood glucose amount was analyzed using glucose meter (ACCU-CHEK Active, Germany) as previously reported [31].

\subsection{Statistical Analysis}

Results were expressed as mean \pm SEM (Standard Error of Mean). We used one-way ANOVA to analyze behavioral performance between the different groups (Diet $=$ independent factor) or two-way ANOVA (Diet $\times$ sex $=$ independent factors) followed by post-hoc test when appropriate. Statistical significant was assumed at $\mathrm{p}$-value $<0.05$.

\section{Results}

\subsection{Behavioral Assessment}

\subsubsection{Anxiety-Like Behavior in EPM}

HFD during pregnancy and lactation has induced significant changes of anxiety behavior in the offspring at juvenile stage in EPM. As depicted Figure 1(a), in males, one-way ANOVA revealed that the number of open armentries was significantly reduced in the HFD and HFD + Methyl donors groups when compared to control diet group $(\mathrm{p}<0.01)$. In females, only the group HFD presents significant reduction of open arm entries $(\mathrm{p}<0.05)$, relative to others groups.

Significant anxiolytic effects were found in both HFD and HFD + Methyl donors groups through the decreased time spent in open arm in males $(\mathrm{p}<0.001)$, and in females $(p<0.01)$, relative to control diet group Figure $1(b)$. In the other hand, two-way ANOVA revealed no significant sex $\times$ Diet effect for the number of open entries. However, the significant sex $\times$ Diet was found for time spent $\operatorname{arm}(\mathrm{p}<0.001)$.

\subsubsection{Depression-Like Behavior in the FST}

The juveniles rats of dams fed with HFD during pregnancy and lactation exhibite a depression-like behavior. One-way ANOVA showed a significant increased of immobility time $(\mathrm{p}<0.001)$ in both sexes fed with HFD Figure 2 . However, post-hoc analysis revealed the immobility time was different when compared the HFD and the HF-D+ methyl donors $(\mathrm{p}<0.001)$, in both sexes male and female Figure 2 . The sex $\times$ Diet effect was reported to time of immobility which measures depression-like behavior $(\mathrm{p}<0.05)$.

\subsubsection{Behavioral Performance in Y-Maze}

As showed Figure 3, a significant reduction of \% alternation in Y-maze associated to alteration of memory ability was found in offspring of dams fed to HFD $(\mathrm{p}<0.001)$, and in group fed to HFD + Methyl donors $(\mathrm{p}<0.05)$. Females group 
(a)

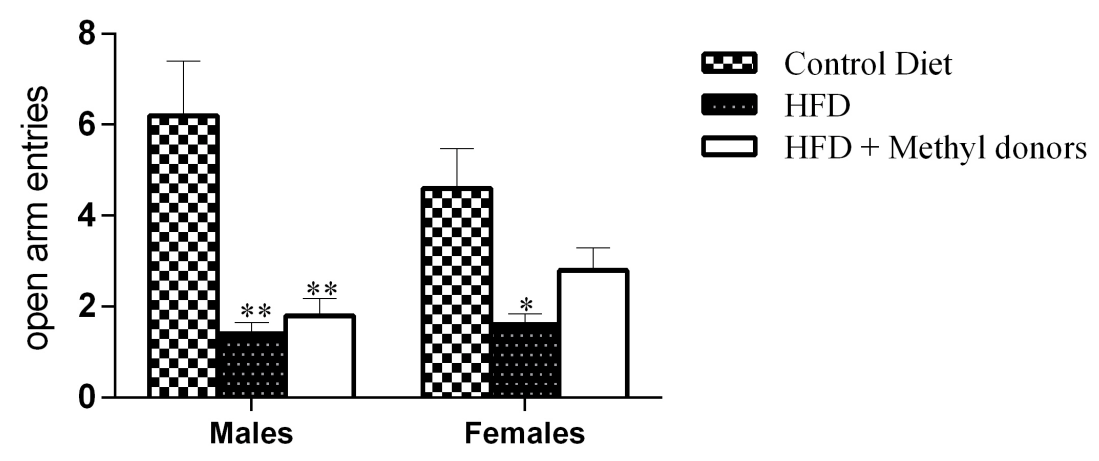

(b)

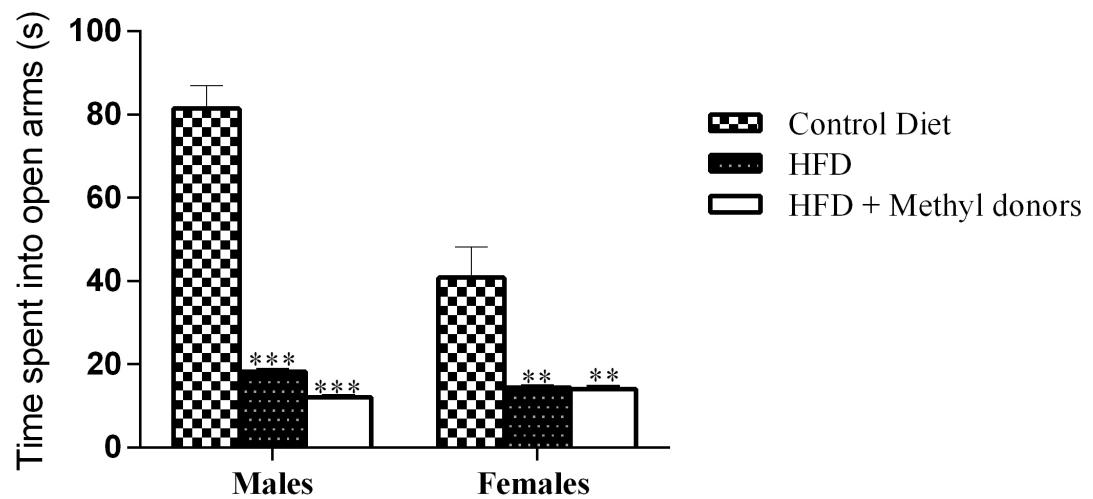

Figure 1. Effect of HFD and High Fructose + methyl donors diet on Anxiety-like behavior in EPM (a) number open-arm entries, (b) time spent into open arms. Data expressed as Mean $\pm \mathrm{SEM}{ }^{*} \mathrm{p}<0.05 ;{ }^{* *} \mathrm{p}<0.01 ;{ }^{* *} \mathrm{p}<0.001\left({ }^{*}\right)$ indicates comparison between all diet groups (One-Way ANOVA).

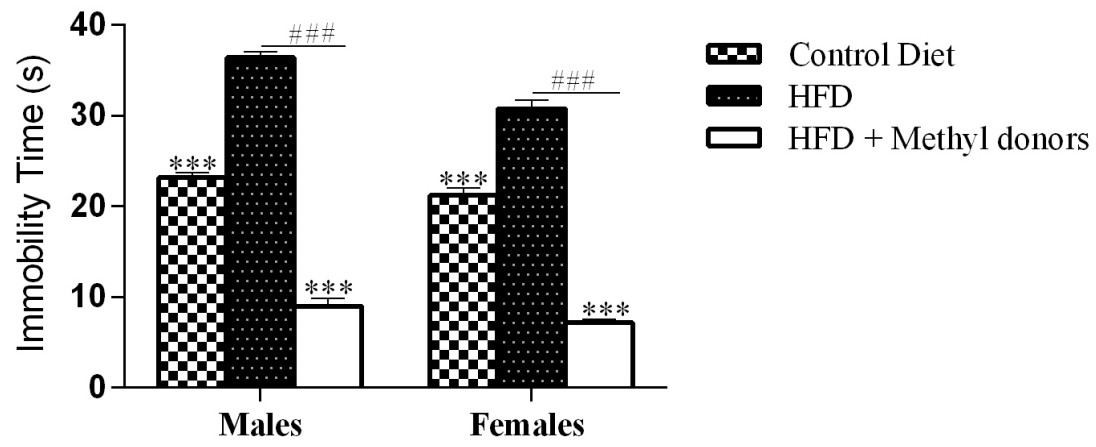

Figure 2. Effect of HFD and High Fructose + Methyl donor diet on Depression-like behavior in FST Immobility time expressed as Mean \pm SEM. ${ }^{* * *}$ p $<0.001$, $\left({ }^{*}\right)$ indicates comparison between all diet groups, ${ }^{\# \# \#} \mathrm{p}<0.001$, (\#) indicates comparison between HFD and HFD + Methyl donors (One-Way ANOVA/Post-hoc analysis).

of HFD showed a decreased \% alternation $(\mathrm{p}<0.001)$. Post-hoc analysis has revealed a significant difference to $\%$ alternation in both sexes male and female fed to HFD ( $\mathrm{p}<0.001$ ), when compared to HFD + Methyl donors Figure 3. Two-way analysis showed significant sex $\times$ Diet effect for the $\%$ of alternation in Y-maze. 


\subsubsection{Object Recognition Test}

We found that the \% RI was below the threshold of object recognition (50\%) in the rats HFD group Figure 4(a). One-way ANOVA showed no significant difference for this variable in males between different groups, but a significant reduction of $\%$ RI in females fed to HFD ( $p<0.05$ ), when compared to HFD + methyl donors and control diet groups Figure 4(a).

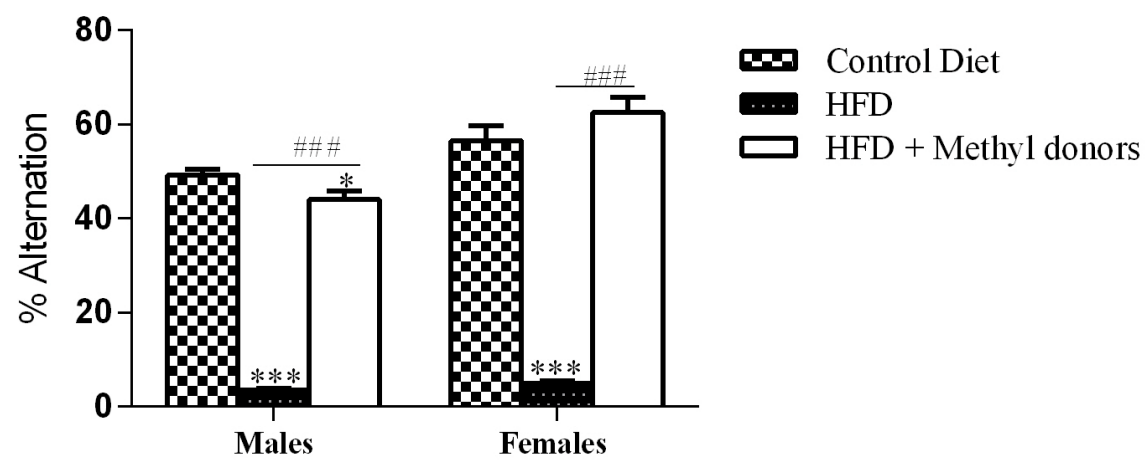

Figure 3. Effect of HFD and High Fructose + Methyl donor diet on memory performance in Y-maze \% of alteration expressed as Mean \pm SEM. ${ }^{\star} \mathrm{p}<0.05 ;{ }^{* *} \mathrm{p}<0.001,\left({ }^{\star}\right)$ indicates comparison between all diet groups ${ }^{\# \#} \mathrm{p}<0.001$, (\#) indicates comparison between HFD and HFD + Methyl donors (One-Way ANOVA/Post-hoc analysis).

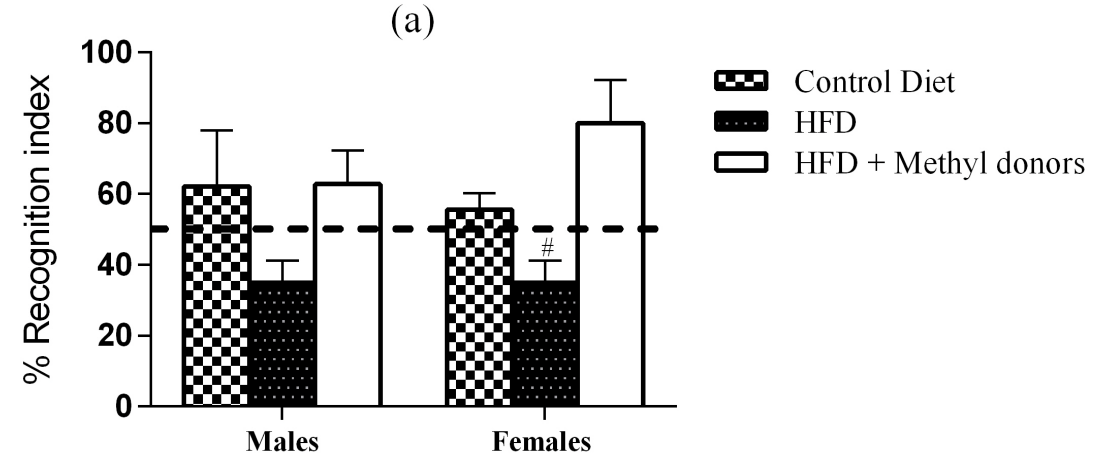

(b)

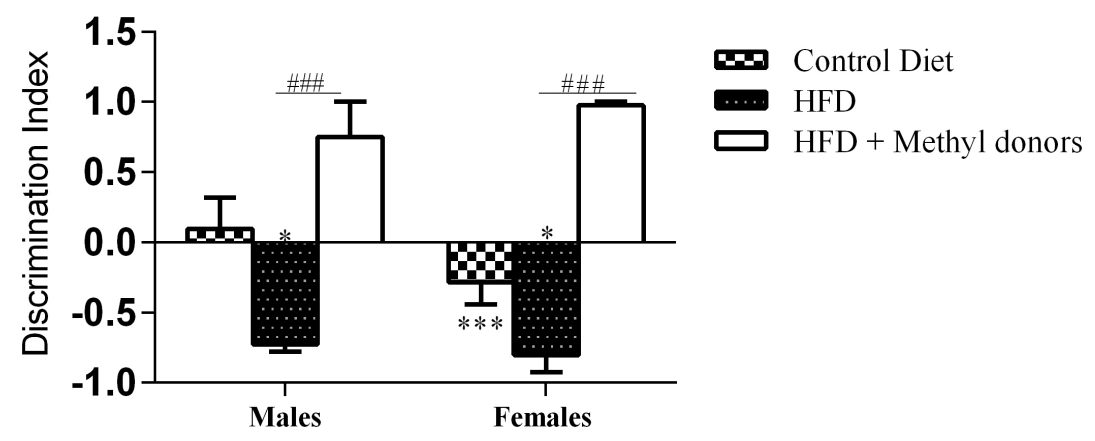

Figure 4. Effect of HFD and High Fructose + Methyl donors diet on memory performance in the Object-recognition task. (a) \% Recognition index, (b) Discrimination index. Data expressed as Mean \pm SEM ${ }^{*} \mathrm{p}<0.05,{ }^{* * *} \mathrm{p}<0.001\left(^{*}\right)$ indicates comparison between all diet groups, ${ }^{\# \# \#}$ p $<0.001$, (\#) indicates comparisonon between HFD and HFD + Methyl donors (One-Way ANOVA/Post-hocanalysis). 
Indeed, the juveniles male rats of dams fed to HFD showed significant preference for familiar object through the DI $(\mathrm{p}<0.05)$, when compared to control diet and HFD + Methyl donors groups Figure 4(b). The DI was also important in HFD + methyl donors group relative to HFD group ( $<<0.001)$ Figure $4(\mathrm{~b})$. In females, the familiar object preference was significant in control diet group $(\mathrm{p}$ $<0.001)$, and in HFD ( $<$ 0.001) relative to HFD + Methyl donors group. However, the ID was reduced in HFD $(p<0.05)$ when compared to control diet group.

No significant sex $\times$ Diet observed for the IR as well as ID variables in the object recognition test.

\subsubsection{Blood Glucose Tolerance Induced after HFD or HFD + Methyl Donors}

At T0, before to $2 \mathrm{~g} / \mathrm{kg}$ i.p of glucose, there is no significant difference in the blood glucose concentration between the groups Figure 5(a). Then, after injection, at T30 blood glucose concentration increased in all groups, and decreased up T120 excepted to the group fed to HFD ( $\mathrm{p}<0.001)$. In females, the blood

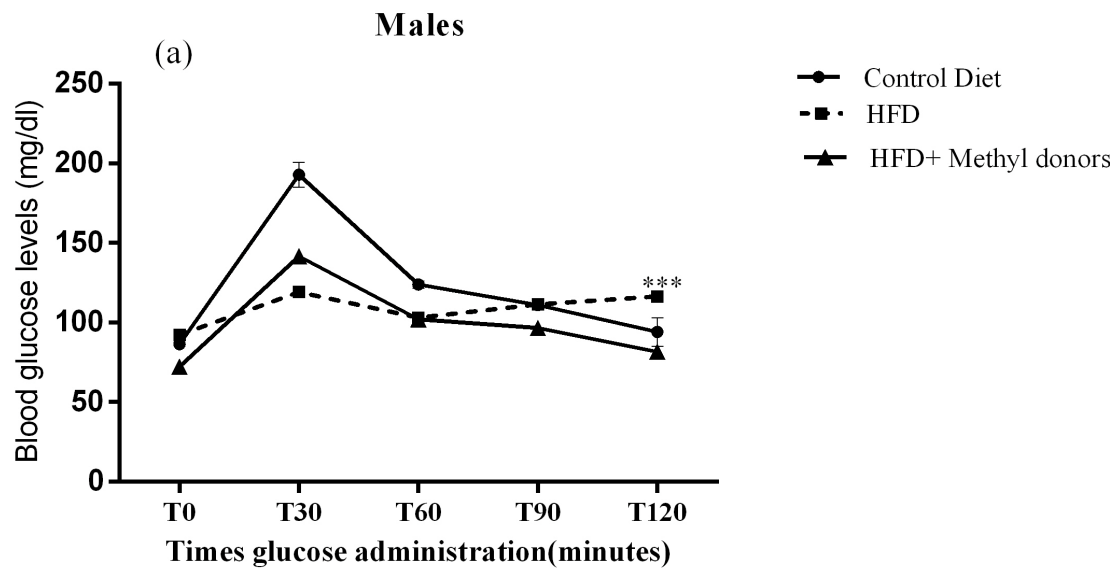

Females

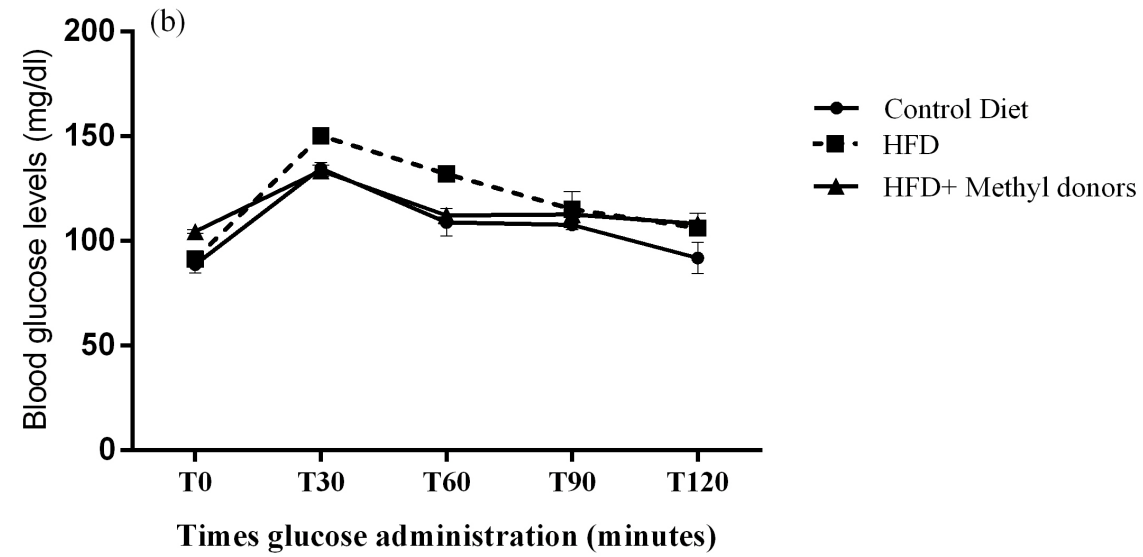

Figure 5. Effect of HFD and High Fructose + Methyl donor diet on blood glucose tolerance Blood concentration in males (a) and in females (b). Data expressed as Mean \pm SEM ${ }^{* * *} \mathrm{p}<0.001$, comparison between diet groups (ANOVA repeated measures). 
glucose level increased at T30, differently observed in males, the decreased blood glucose concentration in all group at T120 Figure 5(b).

\section{Discussion}

To our knowledge, current study examines for first time the risk of maternal nutritionnal programming with HFD during pregnancy and lactation on emotional and cognitive behaviors of the offspring (both sexes of 2 months old), and whether methyl donors supplementation diet may reverse to that. We observed in literature significant effects of HFD on rats cognition [32], and the adverse effects of methyl donor-deficient diet during brain development on memory and anxiety in adulthood in mice [33]. In addition, previous studies demonstrated significant relationship between maternal fructose diet and metabolic disorders in their offspring [34]. However, absent or scarce studies have investigated the possibility behavioral effects on off spring of damsfed with HFD, even if they are feeding after weaning with a standard diet.

Here, behavioral tests revealed that anxiety and depression-like behavior were affected in rats of HFD group at 2 months old, when compared to theses ones of standard diet. We found that rats from HFD group presented a significant reduction of entries and time spent in open arm of EPM, and important increase of immobility time in FS-T. In fact, brain developmental period is sensitive to some exogenous factors like mother nutritional programing. It has been showed that high fructose consumption $(30 \%)$ induces a decrease of the intestinal serotoninergic system by the blockade of serotonin reuptake transpoters [35] [36]. Thus, the anxiogenic effects observed in the off springs of dams fed to high-fat diet could be associated to hyper stimulation of 5-HT $1 \mathrm{~A}$ receptor in the ventral part of hippocampus, well-known to regulate mood and anxiety [37] [38]. According to these authors, the GABA ergic system is also affected. Maternal nutrition based on HFD during pregnancy can produce obesity and related problems which have the potential to affect fetal brain development. In fact, neuroinflammation is strongly associated to obesity and animbalance between proinflammatory molecules and growth factors or neurotransmitters (e.g. Serotonin) early during brain could be a later risk for development of psychiatric disorders including anxiety and depression [39]. On the other hand, our results supported a sex difference effect of HFD-induced anxiety-related behavior; males are more affected than females. Similar observation has been made for depression-like behavior in FST. This is inconsistent with some others showing that males from pregnant and lactation dams fed to HFD-diet have displayed significant psychiatry disorders (anxiety and depression-like be-behavior) than females [40].

In current experiment, the diet with fructose lacked nutrients rich in methyl donors. In fact, as reported in a past study, a deprivation of methyl donors diet in gestational rat dams induced long-lasting disabilities of exploratory activity in their pups [10]. We have found that the group having received HFD with a supplementation of methyl donors (Folic acid, Cholin, betain, L-methionin and Vi- 
tamin B12) had an improved behavior in EPM and FST. It has been clearly shown that maternal diet with supplementation in methyl donor changes gene expression in central nervous system and global DNA hypomethylation in prefrontal cortex [41]. Epigenetic regulation through DNA methylation or histone acetylation is essential factors in the control of psychiatric disorders such as depression and anxiety [42] [43]. Besides, methyl donors components are involved in some neurotransmitters synthesis namely dopamine, adrenaline, serotonin or acetylcholine known to be involved in regulation of depression state [44], as reported reduction of depression state of juveniles of dams fed to HFD and a methyl donors dietary. This study demonstrated that offspring of HFD group presented deterioration of cognitive performance, with deficits of spatial working memory and recognition memory occurring in behavioral tests compared to both standard diet and HF + methyl donors diet groups. We also found the benefit effects of methyl donors' supplementation on cognitive abilities. Our results are in agreement with previous study supporting that undernu-trition of maternal during pre-conception, gestation and lactation may induce adverse effects on brain development and cognitive performance using 8-arm radial maze [45].

The relationship between HFD and the memory impairments is not significantly elucidated. However, a past research reported the effect of HFD-induced neuroinflammation [46]. Further studies evoked that the proinflammatory cytokineslike IL-1 $\beta$, IL- 6 or TNF- $\alpha$ alter the hippocampal neurogenesis and synapto genes is processes which are essential for memory formation [47] [48] [49]. For instance, four weeks for fructose or sucrose diet but not free glucose, neurogenes is in the hippocampus was reduced to approximately $40 \%$ [50]. That reinforces the hypothesis about HFD which impairs memory through the slowdown of neurogenesis.

We observed also that the female offspring rats of HFD group performed better in spatial and recognition memory tests than males. That could be due to the neuroprotective effect of estradiol which mediates modulation of long termpotentiation in the CA1 hippocampal neurons [51].

Importantly, maternal nutrition status could influence the phenotype of offspring. In present study, HFD of dams with depletion to methyldonors component had pupssuffering to a memory dysfunction. A past study reported similar observation in which pups of dams with diet lacking methyl donors showed long-lasting disabilities of learning and memory [10], and reduction of thickness of CA1 pyramidal layer in the hippocampus [52]. This observation shows the important role of methyl donors in the brain development and its derived functions, as reported in current experiment the benefit effects of supplementation diet with methyl donors for alleviating adverse health outcomes of HFD. In fact, the group of HFD with methyl donors' supplementation displayed a best performance in cognitive test compared to those ones fed only with HFD. Methyl donors is a factor of regulation of epigenetic mechanisms well-known as DNA methylation and histone acetylation involved actively in control of gene expres- 
sion supporting memory formation [53] [54] [55] [56]. Otherwise, a previous paper reported that methyl donors' supplementation diet induces an increasing of NMDA receptor subunit, NR2B gene expression in hippocampal cells [33]. NMDA receptor though NR2B mediates memory acquisition, consolidation and recollection of information [57]. It has been reported also that deficiency diet of some methyl donors (Zinc, folic acid or choline) during gestational and lactation phase in mice causes memory defects in their offspring, neuronal apoptosis increasing and decreasing of cell proliferation [58] [59] [60] [61].

As psychiatric disorders and cognitive function impaired were significantly found in rats from dams fed with $23 \%$ HFD during prenatal and pre-weaning period when compared to standard diet or HF+ methyl donors groups, our study reported evidence of high level of blood glucose. After, the fasting period, blood concentration of glucose was growing at T30 after tail glucose injection and remained constant in males, but decreases slowly in females. It was found in the offspring which Damfed to $20 \%$ HF-D during pre-conception, pregnancy and lactation, some signs of metabolic syndrome as high blood glucose level, triglyceride, LDL, VLDL, and significant body weight gain [34]. Several others studies have investigated the physiological and metabolic disorders induced by the HFD [15] [16] [62] [63]. Although, most of studies have focused on the effects of maternal high fat diet on offspring physiology [41] [63] [64] [65], but the fructose and by-products are precursor of free fatty acid circulating [15] [16]. In addition, the increased of free fatty acid and other derivate substances of fructose increase liver gluconeogenic pathway [12] [16]. The metabolism subsequent effects of HFD consist to generate high level of free fatty acid which can causes insulin insensitivity leading to blood glucose intolerance [12].

Taken together, these findings indicate that cognitive impairment in rats of HFD group is due to deficit of free circulating glucose which is strictly used as nutrients for brain.

We noted that the level of glucose intolerance revealed to be important in male rats relative to that of females. The sex difference effect of blood glucose concentration could be based on the key role of female steroid hormones in hepatic metabolism [66] [67].

Our research outcomes showed that the HFD with methyl donors' supplementation revealed a blood glucose level progression similar to that observed in control diet rats. In fact, it has been reported in a past study a tolerance of blood glucose in progeny whose maternal fed with a supplementation diet including folic acid [68]. The relationship between methyl donors' action mechanisms and glucose tolerance is not still clear. However, a possible effect may be due to methylation of insulin gene involved in the blood glucose level regulation.

In the light of our results, maternal HFD early in prenatal and postnatal period is considered as great risk factor to apparition later, of neurobehavioral disorders or cognitive impairments in offspring. Although, most of experiments have emphasized on detrimental health effect of High fat diet, the outcomes of 
current study revealed to be complementarity to the previous ones, because of metabolic link between Fructose and fat diet. Additional studies are needed to investigate the epigenetic mechanisms and insulin resistance signaling associated to HFD in early life.

\section{References}

[1] Park, Y.K. and Yetley, E.A. (1993) Intakes and Food Sources of Fructose in the United States. The American Journal of Clinical Nutrition, 58, 737S-747S.

[2] Tamashiro, K.L., Terrillion, C.E., Hyun, J., Koenig, J.I. and Moran, T.H. (2009) Prenatal Stress or High-Fat Diet Increases Susceptibility to Diet-Induced Obesity in Rat Offspring. Diabetes, 58, 1116-1125. https://doi.org/10.2337/db08-1129

[3] Sullivan, E.L., Smith, M.S. and Grove, K.L. (2011) Perinatal Exposure to High-Fat Diet Programs Energy Balance, Metabolism and Behavior in Adulthood. Neuroendocrinology, 93, 1-8. https://doi.org/10.1159/000322038

[4] Ashino, N.G., Saito, K.N., Souza, F.D., Nakutz, F.S., Roman, E.A., et al. (2012) Maternal High-Fat Feeding through Pregnancy and Lactation Predisposes Mouse Offspring to Molecular Insulin Resistance and Fatty Liver. Journal of Nutritional Biochemistry, 23, 241-348. https://doi.org/10.1016/j.jnutbio.2010.12.011

[5] Rother, E., Kuschewski, R., Alcazar, M.A., Oberthuer, A., Bae-Gartz, I., et al. (2012) Hypothalamic JNK1 and IKKb Activation and Impaired Early Postnatal Glucose Metabolism after Maternal Perinatal High-Fat Feeding. Endocrinology, 153, 770-781. https://doi.org/10.1210/en.2011-1589

[6] Vucetic, Z., Kimmel, J., Totoki, K., Hollenbeck, E. and Reyes, T.M. (2010) Maternal High-Fat Diet Alters Methylation and Gene Expression of Dopamine and OpioidRelated Genes. Endocrinology, 151, 4756-4764. https://doi.org/10.1210/en.2010-0505

[7] Ludwig, D.S., Peterson, K.E. and Gortmaker, S.L. (2001) Relation between Consumption of Sugar-Sweetened Drinks and Childhood Obesity: A Prospective, Observational Analysis. Lancet, 357, 505-508. https://doi.org/10.1016/S0140-6736(00)04041-1

[8] Rizkalla, S.W. (2010) Health Implications of Fructose Consumption: A Review of Recent Data. Nutrition \& Metabolism (Lond), 7, 82.

https://doi.org/10.1186/1743-7075-7-82

[9] Catena, C., Giacchetti, G., et al. (2003) Cellular Mechanisms of Insulin Resistance in Rats with Fructose-Induced Hypertension. American Journal of Hypertension, 16, 973-978. https://doi.org/10.1016/S0895-7061(03)01002-1

[10] Blaise, S.A., Nedelec, E., Schroeder, H., Alberto, J.M., Bossenmeyer-Pourie, C., et al. (2007) Gestational Vitamin B Deficiency Leads to Homocysteine-Associated Brain Apoptosis and Alters Neurobehavioral Development in Rats. The American Journal of Pathology, 170, 667-679. https://doi.org/10.2353/ajpath.2007.060339

[11] Cave, M., Deaciuc, I., et al. (2007) Nonalcoholic Fatty Liver Disease: Predisposing Factors and the Role of Nutrition. Journal of Nutritional Biochemistry, 18, 184-195. https://doi.org/10.1016/j.jnutbio.2006.12.006

[12] Elliott, S.S., Keim, N.L., et al. (2002) Fructose, Weight Gain, and the Insulin Resistance Syndrome. The American Journal of Clinical Nutrition, 76, 911-922.

[13] Hallfrisch, J., Reiser, S. and Prather, E.S. (1983) Blood Lipid Distribution of Hyperinsulinemic Men Consuming Three Levels of Fructose. The American Journal of Clinical Nutrition, 37, 740-748. 
[14] Reaven, G.M. (1982) Effects of Fructose on Lipid Metabolism. The American Journal of Clinical Nutrition, 35, 627.

[15] Kelley, G.L., Allan, G., et al. (2004) High Dietary Fructose Induces a Hepatic Stress Response Resulting in Cholesterol and Lipid Dysregulation. Endocrinology, 145, 548-555. https://doi.org/10.1210/en.2003-1167

[16] Havel, P.J. (2005) Dietary Fructose: Implications for Dysregulation of Energy Homeostasis and Lipid/Carbohydrate Metabolism. Nutrition Reviews, 63, 133-157. https://doi.org/10.1111/j.1753-4887.2005.tb00132.x

[17] Lindqvist, A., Baelemans, A. and Eelanson-Albertsson, C. (2008) Effects of Sucrose, Glucose and Fructose on Peripheral and Central Appetite Signals. Regulatory Peptides, 150, 26-32. https://doi.org/10.1016/j.regpep.2008.06.008

[18] Cooney, C.A., Dave, A.A. and Wolff, G.L. (2002) Maternal Methyl Supplements in Mice Affect Epigenetic Variation and DNA Methylation of Offspring. Journal of Nutrition, 132, 2393S-2400S.

[19] Wolff, G.L., Kodell, R.L., Moore, S.R. and Cooney, C.A. (1998) Maternal Dietary Methyl Supplements Affect Visible Expression of the Avy Gene in Viable Yellow Mice. The FASEB Journal, 12, 949-957.

[20] Torner, L., Toschi, N., Pohlinger, A., Landgraf, R. and Neumann, I.D. (2001) Anxiolytic and Anti-Stress Effects of Brain Prolactin: Improved Efficacy of Antisense Targeting of the Prolactin Receptor by Molecular Modeling. Journal of Neuroscience, 21, 3207-3214.

[21] Guardiola-Lemaitre, B., Lenegre, A. and Porsolt, R.D. (1992) Combined Effects of Diazepam and Melatonin in Two Tests for Anxiolytic Activity in the Mouse. Pharmacology Biochemistry and Behavior, 41, 405-408. https://doi.org/10.1016/0091-3057(92)90118-Y

[22] Hiramatsu, M., Sasaki, M., Nabeshima, T. and Kameyama, T. (1997) Effects of dynorphina (1-13) on Carbonmonoxide-Induced Delayedamnesia in Mice. Pharmacology Biochemistry and Behavior, 56, 73-79.

[23] Sarter, M., Bodewitz, G. and Stephens, D.N. (1988) Attenuation of Scopolamine-Induced Impairment of Spontaneous Alternation Behavior by Antagonist But Not Inverse Agonist and Antagonist b-Carboline. Psychopharmacology, 94, 491-495.

[24] Ennaceur, A. and Delacour, J. (1988) A New One-Trial Test for Neurobiological Studies of Memory in Rats. 1: Behavioral Data. Behavioural Brain Research, 31, 47-59. https://doi.org/10.1016/0166-4328(88)90157-X

[25] Botton, P.H., Costa, M.S., Ardais, A.P., Mioranzza, S., Souza, D.O., da Rocha, J.B. and Porciuncula, L.O. (2010) Caffeine Prevents Disruption of Memory Consolidation in the Inhibitory Avoidance and Novel Object Recognition Tasks by Scopolamine in Adult Mice. Behavioural Brain Research, 214, 254-259. https://doi.org/10.1016/j.bbr.2010.05.034

[26] Aggleton, J.P., Albasser, M.M., Aggleton, D.J., Poirier, G.L. and Pearce, J.M. (2010) Lesions of the Rat Perirhinal Cortex Spare the Acquisition of a Complex Configural Visual Discrimination Yet Impair Object Recognition. Behavioral Neuroscience, 124, 55-68. https://doi.org/10.1037/a0018320

[27] Aubele, T., Kaufman, R., Montalment, F. and Kritzer, M.F. (2008) Effects of Gonadectomy and Hormone Replacement on a Spontaneous Novel Object Recognition Task in Adult Male Rats. Hormones and Behavior, 54, 244-252. https://doi.org/10.1016/j.yhbeh.2008.04.001

[28] Burke, S.N., Wallace, J.L., Nematollahi, S., Uprety, A.R. and Barnes, C.A. (2010) Pattern Separation Deficits May Contribute to Age-Associated Recognition Im- 
pairments. Behavioral Neuroscience, 124, 559-573.

https://doi.org/10.1037/a0020893

[29] Oliveira, A.M.M., Hawk, J.D., Abel, T. and Havekes, R. (2010) Post-Training Reversible Inactivation of the Hippocampus Enhances Novel Object Recognition Memory. Learning \& Memory, 17, 155-160. https://doi.org/10.1101/lm.1625310

[30] Silvers, J.M., Harrod, S.B., Mactutus, C.F. and Booze, R.M. (2007) Automation of the Novel Object Recognition Task for Use in Adolescent Rats. Journal of Neuroscience Methods, 166, 99-103. https://doi.org/10.1016/j.jneumeth.2007.06.032

[31] Morin, N., Visentin, V., Calise, D., Marti, L., Zorzano, A., Testar, X., et al. (2002) Tyramine Stimulates Glucose Uptake in Insulin-Sensitive Tissues in Vitro and in Vivo via Its Oxidation by Amine Oxidases. Journal of Pharmacology and Experimental Therapeutics, 303, 1238-1247. https://doi.org/10.1124/jpet.102.040592

[32] Ross, A.P. (2008) Effects of a High Fructose Diet on Physiology and Cognition in Male Sprague-Dawley Rats. Thesis, Georgia State University. http://scholarworks.gsu.edu/psych_theses/45

[33] Ishii, D., Matsuzawa, D., Matsuda, S., Tomizawa, H., Sutoh, C., et al. (2014) Methyl Donor-Deficient Diet during Development Can Affect Fear and Anxiety in Adulthood in C57BL/6J Mice. PLoS ONE, 9, e105750. https://doi.org/10.1371/journal.pone.0105750

[34] Sari, E., Yeşilkaya, E., Bolat, A., Topal, T., Altan, B., Fidanci, K., Güven, A., et al. (2015) Metabolic and Histopathological Effects of Fructose Intake during Pregestation, Gestation and Lactation in Rats and Their Offspring. JCRPE Journal of Clinical Research in Pediatric Endocrinology, 7, 19-26. https://doi.org/10.4274/jcrpe.1776

[35] Haub, S., Kanuri, G., Volynets, V., Brune, T., Bischoff, S.C. and Bergheim (2009) Serotonin Reuptake Transporter (SERT) Plays a Critical Role in Fructose-Induced Hepatic Steatosis in Mice. Physiology, 298, G335-G344.

[36] Fox, M.A., Jensen, C.L., French, H.T., Stein, A.R., Huang, S.J., Tolliver, T.J., et al. (2008) Neurochemical, Behavioral, and Physiological Effects of Pharmacologically Enhanced Serotonin Levels in Serotonin Transport (SERT)-Deficient Mice. Psychopharmacology (BerI), 201, 203-218. https://doi.org/10.1007/s00213-008-1268-7

[37] Peleg-Raibstein, D., Luca, E. and Wolfrum, C. (2012) Maternal High-Fat Diet in Mice Programs Emotional Behavior in Adulthood. Behavioural Brain Research, 233, 398-404. https://doi.org/10.1016/j.bbr.2012.05.027

[38] Suranyi-Cadotte, B.E., Bodnoff, S.R. and Welner, S.A. (1990) Antidepressant-Anxiolytic Interactions: Involvement of the Benzodiazepine-GABA and Serotonin Systems. Progress in Neuro-Psychopharmacology and Biological Psychiatry, 14, 633-654.

[39] Bolton, J.L. and Bilbo, S.D. (2014) Developmental Programming of Brain and Behavior by Perinatal Diet: Focus on Inflammatory Mechanisms. Dialogues in Clinical Neuroscience, 16, 307-320.

[40] Bilbo Staci, D. and Tsang, V. (2010) Enduring Consequences of Maternal Obesity for Brain Inflammation and Behavior of Offspring. The FASEB Journal, 24, 21042115. https://doi.org/10.1096/fj.09-144014

[41] Carlin, J., George, R. and Reyes, T.M. (2013) Methyl Donor Supplementation Blocks the Adverse Effects of Maternal High Fat Diet on Offspring Physiology. PLoS ONE, 8, e63549. https://doi.org/10.1371/journal.pone.0063549

[42] Fuchikami, M., Morinobu, S., Segawa, M., Okamoto, Y., Yamawaki, S., Ozaki, N., et al. (2011) DNA Methylation Profiles of the Brain-Derived Neurotrophic Factor (BDNF) Gene as a Potent Diagnostic Biomarker in Major Depression. PLoS ONE, 
6, e23881. https://doi.org/10.1371/journal.pone.0023881

[43] Smith, A.K., Conneely, K.N., Kilaru, V., Mercer, K.B., Weiss, T.E., Bradley, B., Ressler, K.J., et al. (2011) Differential Immune System DNA Methylation and Cytokine Regulation in Post-Traumatic Stress Disorder. American Journal of Medical Genetics Part B: Neuropsychiatric Genetics, 156, 700-708.

https://doi.org/10.1002/ajmg.b.31212

[44] Miller, A.L. (2008) The Methylation, Neurotransmitter, and Antioxidant Connections between Folate and Depression. Alternative Medicine Review. A Journal of Clinical Therapeutic, 13, 216-226.

[45] Ranade, S.C., Rose, A., Rao, M., Gallego, J., Gressens, P. and Mani, S. (2008) Different Types of Nutritional Deficiencies Affect Different Domains of Spatial Memory Function Checked in a Radial Arm Maze. Neuroscience, 152, 859-866. https://doi.org/10.1016/j.neuroscience.2008.01.002

[46] Gersch, M.S., Mu, W., Cirillo, P., Reungjui, S., Zhang, L., Roncal, C., Sautin, Y.Y., Johnson, R.J. and Nakagawa, T. (2007) Fructose, But Not Dextrose, Accelerates the Progression of Chronic Kidney Disease. American Journal of Physiology-Renal Physiology, 293, F1256-F1261. https://doi.org/10.1152/ajprenal.00181.2007

[47] Koo, J.W. and Duman, R.S. (2008) IL-1beta Is an Essential Mediator of the Antineurogenic and Anhedonic Effects of Stress. Proceedings of the National Academy of Sciences, 105, 751-756. https://doi.org/10.1073/pnas.0708092105

[48] Vallieres, L., Campbell, I.L., Gage, F.H. and Sawchenko, P.E. (2002) Reduced Hippocampal Neurogenesis in Adult Transgenicmice with Chronicastrocytic Production of Interleukin-6. Journal of Neuroscience, 22, 486-492.

[49] Iosif, R.E., Ekdahl, C.T., Ahlenius, H., Pronk, C.J., Bonde, S., Kokaia, Z., Jacobsen, S.E. and Lindvall, O. (2006) Tumornecrosis Factor Receptor 1 Is a Negative Regulator of Progenitor Proliferation in Adult Hippocampal Neurogenesis. Journal of Neuroscience, 26, 9703-9712. https://doi.org/10.1523/JNEUROSCI.2723-06.2006

[50] Van der Borght, K., Köhnke, R., Göransson, N., Deierborg, T., Brundin, P., Erlanson Albertsson, C. and Lindqvist, A. (2011) Reduced Neurogenesis in the Rat Hippocampus Following High Fructose Consumption. Regulatory Peptides, 167, 26-30. https://doi.org/10.1016/j.regpep.2010.11.002

[51] Smith, C.C., Vedder, L.C. and McMahon, L.L. (2009) Estradiol and the Relationship between Dendritic Spines, NR2B Containing NMDA Receptors, and the Magnitude of Long-Term Potentiation at Hippocampal CA3-CA1 Synapses. Psychoneuroendocrinology, 34S, S130-S142. https://doi.org/10.1016/j.psyneuen.2009.06.003

[52] Daval, J.L., Blaise, S. and Gueant, J.L. (2009) Vitamin B Deficiency Causes Neural Cell Loss and Cognitive Impairment in the Developing Rat. Proceedings of the National Academy of Sciences, 106, E1.

[53] Holliday, R. and Pugh, J.E. (1975) DNA Modification Mechanisms and Gene Activity during Development. Science, 187, 226-232.

https://doi.org/10.1126/science.1111098

[54] Turner, B.M. (1991) Histone Acetylation and Control of Gene Expression. Journal of Cell Science, 99, 13-20.

[55] Fuchikami, M., Yamamoto, S., Morinobu, S., Takei, S. and Yamawaki, S. (2010) Epigenetic Regulation of BDNF Gene in Response to Stress. Psychiatry Investigation, 7, 251-256. https://doi.org/10.4306/pi.2010.7.4.251

[56] Miller, C.A. and Sweatt, J.D. (2007) Covalent Modification of DNA Regulates Memory Formation. Neuron, 53, 857-869.

https://doi.org/10.1016/j.neuron.2007.02.022 
[57] Shimizu, E., Tang, Y.P., Rampon, C. and Tsien, J.Z. (2000) NMDA Receptor-Dependent Synaptic Reinforcement as a Crucial Process for Memory Consolidation. Science, 290, 1170-1174. https://doi.org/10.1126/science.290.5494.1170

[58] Niculescu, M.D., Craciunescu, C.N. and Zeisel, S.H. (2006) Dietary Choline Deficiency Alters Global and Gene-Specific DNA Methylation in the Developing Hippocampus of Mouse Fetal Brains. The FASEB Journal, 20, 43-49. https://doi.org/10.1096/fj.05-4707com

[59] Yu, X., Jin, L. and Zhang, X. (2013) Effects of Maternal Mild Zinc Deficiency and Zinc Supplementation in Offspring on Spatial Memory and Hippocampal Neuronal Ultrastructural Changes. Nutrition, 29, 457-461. https://doi.org/10.1016/j.nut.2012.09.002

[60] Craciunescu, C.N., Albright, C.D., Mar, M.H., Song, J. and Zeisel, S.H. (2003) Choline Availability during Embryonic Development Alters Progenitor Cell Mitosis in Developing Mouse Hippocampus. Journal of Nutrition, 133, 3614-3618.

[61] Craciunescu, C.N., Brown, E.C., Mar, M.H., Albright, C.D., Nadeau, M.R. and Zeisel, S.H. (2004) Folic Acid Deficiency during Late Gestation Decreases Progenitor Cell Proliferation and Increases Apoptosis in Fetal Mouse Brain. Journal of Nutrition, 134, 162-166.

[62] Topping, D.D.L. and Mayes, P.P.A. (1972) The Immediate Effects of Insulin and Fructose on the Metabolism of the Perfused Liver. Changes in Lipoprotein Secretion, Fatty Acid Oxidation and Esterification, Lipogenesis and Carbohydrate Metabolism. The Biochemical Journal, 126, 295-311.

[63] Ong, Z.Y. and Muhlhausler, B.S. (2011) Maternal “Junk-Food” Feeding of Rat Dams Alters Food Choices and Development of the Mesolimbic Reward Pathway in the Offspring. The FASEB Journal, 25, 2167-2179.

https://doi.org/10.1096/fj.10-178392

[64] Engeham, S.F. and Haase, A. (2010) Supplementation of a Maternal Lowprotein Diet in Rat Pregnancy with Folic Acid Ameliorates Programming Effects upon Feeding Behaviour in the Absence of Disturbances to the Methionine Homocysteine Cycle. British Journal of Nutrition, 103, 996-1007. https://doi.org/10.1017/S0007114509992662

[65] Bayol, S.A., Farrington, S.J. and Stickland, N.C. (2007) A Maternal "Junk Food" Diet in Pregnancy and Lactation Promotes an Exacerbated Taste for "Junk Food" and a Greater Propensity for Obesity in Rat Offspring. British Journal of Nutrition, 98, 843-851. https://doi.org/10.1017/S0007114507812037

[66] Studer, R.K. and Borle, A.B. (1982) The Relative Role of Calcium and Camp in Phosphorylase Activation by Catecholamines. The Journal of Biological Chemistry, 257, 7987-7993.

[67] Macotela, Y., Boucher, J., Tran, T.T. and Kahn, C.R. (2009) Sex and Depot Differences in Adipocyte Insulin Sensitivity and Glucose Metabolism. Diabetes, 58, 803 812. https://doi.org/10.2337/db08-1054

[68] Chmurzynska, A., Stachowiak, M., Gawecki, J., Pruszynska-Oszmalek, E. and Tubacka, M. (2011) Protein and Folic Acid Content in the Maternal Diet Determine Lipid Metabolism and Response to High-Fat Feeding in Rat Progeny in an AgeDependent Manner. Genes \& Nutrition, 7, 253.

https://doi.org/10.1007/s12263-011-0253-7 